\title{
El problema de los pequeños Municipios en la Provincia de Teruel
}

\author{
por \\ JULIO PELAYO MARRACO \\ Secretario de la Diputación provincial de Teruel
}

Se ha expuesto oficialmente la conveniencia de resolver el problema del pequeño Municipio en España, o sea, de aquellos Municipios que no alcanzan el promedio de 500 habitantes y un presupuesto superior a $\mathbf{1 0 0 . 0 0 0}$ pesetas. La solución presentada para este problema no ha sido aún formulada oficialmente, mas es lo cierto que por algunos municipalistas se han proyectado algunas soluciones: Unas drásticas, como es la supresión total del Municipio afectado, y otras, con menos radicalismo, declarando a estos Municipios capitidisminuídos. Estimamos que tanto en un caso como en otro se carece de solidez naturalista, sin rigor sociológico, aunque abunden razones puramente estadísticas, con lo que se adolece de casuísmo y de imprecisión para abordar este problema de gran significado nacional y desde luego el más acuciante en nuestras Provincias.

Su estudio exige una comprensión profunda del problema pues el humanismo que encierra exige conocerlo con el máximo cariño; tan hondo es el problema que palpita en nuestros pequeños Municipios españoles, y que se manifiesta con dramático sobrecogimiento para quienes vivimos entrañablemente unidos a él por razones pró́esionales.

En esta Povincia nos hallamos con 282 Municipios en total, de los quie $\mathbf{9 r}$ son menores de $\mathbf{5 0 0}$ habitantes y $\mathbf{1 1 1}$ no superan la 
cifra tope de $\mathbf{1 0 0 . 0 0 0}$ pesetas en sus respectivos presupuestos dé Ingresos.y. Gastos. Mas si.sumamos los Municipios que por girar. alrededor de estas cifras topes merecerían ser agregados a dichó indice de Municipios menores, vemos que, por el juego de uno u otro de los factores enunciados - coincidentes en casi la totalidad de los casos - significaría la supresión masiva de aproximadamente 150 Municipios, es decir, 53,15 por 100. Ello implicaría a nuestro juicio una acción anti-Municipio, considerablemente devastadora.

Cierto es que til problema que engendra la supresión de estos Municipios es motivado por una vida angosta y pobre. por lo que mal pueden retribuir decorosamente a su funcionario, es decir, el Secretario. En consecuencia, éste se recluta al margen del Cuerpo Nacional, lo que es causa de insolvencia e irresponsabilidad, en términos genéricos, salvo magníficas excepciones que hemos conocido. Tál supresión a priori de estos Municipios y su conversión en Entidades locales menores, seria desacertada, a nuestro juicio, por cuanto llevaría implícita la supeditación del Municipio suprimido al de su nueva agregación, cuyo Alcalde designaría el Pedáneo, precisamente con un Municipio que, como limítrofe, hay que presumir existan las diferencias acostumbradas en estos casos, sobre aprovechamiento de aguas, pastos, leñas y comunicaciones, todo lo cual, por simple que sea el caso, origina entre nuestros pueblos un estado de apasionamiento morboso. Tal reducción de categoría politica significaría un impacto sentimental, un complejo de inferioridad desalentador para estas vecindades, tanto que serviria de estímulo a tan pobre gente rural, sin preparación cultural, en su tendencia. al éxodo, abandonando sus campos y motivando la concentración en las ciudades, lo que es causa del paro obrero y de los suburbios, problemas ambos de mucha complejidad y de difícil solución. Se ha dicho reiteradamente que este abandono de nuestros pueblos es producido principalmente por el deseo de huir de un ambiente material económico y social deprimido, sin expectativas de mejoramiento personal. Mas si tal ausencia gregaria de nuestros pueblos resulta incontenible, quizás logremos hacer más grata la vida al vecindario 
que permanece, dotando y acondicionando estos núcleos rurales de los servicios públicos esenciales e imprescindibles en los tiempos presentes.

A fin de obviar tal inconveniente, nacido de una solución drástica como la expuesta, que supondría la despersonalización jurídica de nuestros pequeños Municipios, convendría estudiar un procedimiento, siquiera provisional, a vía de ensayo, de fácil aplicación y carente de riesgo. Consistiría en respetar la condición político-jurídica de tales Municipios, pero gobernados en vez de por un Ayuntamiento, por una Junta vecinal, o sea en forma análoga a las Entidades Locales menores. Mas como tal denominación es un galicismo centralista sin base histórica en nuestra $\mathrm{Pa}$ tria, convendría restablecer la auténtica denominación de "Concejos" con el aditamento "Rurales" a modo de sustantivo, que son los que tienen verdadera raigambre según vemos en los viejos documentos, y que aún se observa cuando dicen "citar a Concejo" o "ir de concejada". Estos Concejos rurales constituiríanse a su vez en Agrupación, mediante un Ayuntamiento comarcal, sin Término propio, pues cada Concejo conservaría el suyo. Este Ayuntamiento comarcal, con sede en la capital del Partido u otra población del mismo, según conviniese, estaría compuesto por todos los Aicaldes pedáneos presididos por el Diputado-provincial respectivo o por personalidad política de relieve en la Comarca. La Secretaría sería desempeñada por funcionario letrado del Cuerpo Nacional de primera o de segunda categoría. Tal funcionario, con el fin de investir su función de un mayor relieve y eficacia, dependería jerárquicamente de la Administración Central. Su retribución sería a cargo de la Diputación Pròvincial, con cuya Corporación colaboraría íntimamente en el orden administrativo a los fines de Cooperación provincial y de Servicios Técnicos. Los Municipios así agrupados verian reducida su actividad burocrática en forma considerabie y la que subsistiese, por simplicidad, podría ser desempeñada por el Dersonal del Magisterio Primario, destinacio en la localidad, oportunamente gratificado. En todo caso, esta misma actividad con los Organismos superiores, lo sería a través de la Secretaría comarcal, que asumiría íntegramente 
esta competència, y aún algunos servicios, como los censales y los de Contribuciones y arbitrios de toda índole, que podrían ser formalizados por las oficinas de la Diputación en condiciones de absoluta gratuidad para el Concejo rural. En definitiva y por cuanto, como decimos antes, la personalidad juridica de estos Municipios rurales sería íntegramente respetada, el gobierno patrimonial de tales Entidades, correspondería a la Junta vecinal, como antes lo hacía el Ayuntamiento, aunque bajo la intervención o supervisión del Presidente o Diputado comarcal. Consideramos que el gobierno de estos Municipios menores, por la singularidad que para ello se ofrece en cada caso, merecería la redacción de una Ordenanza adaptada al medio ambiente, aunque obedeciendo a unas líneas generales, sobre cuya base la redactaría la Secretaría, la aprobaría el Concejo y la sancionaría la Superioridad, previo informe de la Diputación.

Observamós que en estos momentos se proyecta preferentemente la actividad local al servicio de las grandes demarcaciones, mas lo que abundan en España son precisamente los pequeños Municipios rurales; tanto que según nos dice la Estadística, son 3.219; los que no alcanzan presupuesto de 100.000 pesetas. De aquí la conveniencia de lograr una nueva estructura político-administrativa para estas pequeñas Entidades. La vigente división administrativa en Partidos judiciales, es útil tan sólo para determinados fines administrativos. En cambio, carece de significado político alguno tanto más en las Provincias montañosas, en las que la Comarca natural es de características histórico-geográficas. No obstante, resulta evidente que la actual división judicial, aun sometida en estos momentos a revisión, ha alcanzado un valor innegable en estas otras zonas del territorio nacional, en las que tras un siglo de existencia se mantiene vigente para algunos fines jurídico-administrativos, pero que igualmente podría utilizarse en una forma muy convencional para este fin político a que aludimos, dado que en estas Provincias, al contrario que en las del Norte, la hidrografía, por su escaso relieve, no es un factor geográfico decisivo: En estas Provincias, la Comarca natural es de una extensión desproporcionada. Tenemos aquí una 
Comarca natural, la denominada Tierra Baja, que alcanza a cuatro Partidos Judiciales, cuya Capital comercial es la ciudad de Alcañiz, antiguo Corregimiento, de gran valor histórico, pero que hoy día mantiene, en razón a más fáciles comunicaciones, una relación más íntima en el orden económico y comercial con otras Provincias limitrofes, con preferencia a esta Capital, salvo motivaciones de carácter político-administrativo de carácter provincial. La otra zona es el altiplano propiamente turolense. Podrian señalarse otras comarcas geográficas enclavadas en una misma serranía, pero su delimitación sería imprecisa para nuestros fines.

Con la agrupación de estos pequeños Municipios - verdaderas infraestructuras políticas de la Nación- en otra entidad de mayor volumen, se lograría en un futuro próximo la desaparición dé localismos aldeanos, siempre negativos, que serian sustituídos por una visión más amplia y operativa, más efectiva hacia el fin primordial de poner en línea de progreso las condiciones de su vida pública municipal.

En definitiva, la solución que nos atrevemos a proponer entraña dos fórmulas: De una parte la supresión de Secretarias, imposibilitadas para su dotación mínima, y de otra, la fijación en pleno medio rural de un funcionario especializado, con actuación independiente $\mathrm{y}$ visión amplia, por lo que alcanzaria una finalidad de la mayor consideración social, que le permitiria conocer el fondo mismo del problema municipal en nuestra Patria y señalar los cauces adecuados para una reforma definitiva. En otro orden de razones la calificación política del Jefe de la nueva Administración comarcal, sería un antecedente de lo que algún día podría constituir, a nuestro juicio, la "summa" municipal en España, es decir, que tal jefatura en un grado medio fuera ejercida por un órgano profesional.

Estos pequeños Municipios no son una simple abstración, por olvidada y pobre menos evidente, y como los seres débiles exigen que la política naciona! les dedique sus mejores cuidados y sus desvelos de más firme ley. $Y$ así, con esta nueva área políticogeográfica, mediante una supramunicipatización, se lograria por 
el momento infundir nueva vitalidad a nuestro pequeño Múnicipio, que yace adormecido en su historia, impedido por carencia de medios para toda reforma o evolución, o sea, que en reducida escala contribuiriamos a preparar el ambiente para alcanzar en su día transformaciones de mayor importancia que la que ahora proyectamos en favor de estos humildes pueblos, hoy sometidos a una paulatina decrepitud, si bien son objeto del más caro interés por parte de las autoridades centrales y provinciales, al gozar desde los últimos años del beneficioso sistema de la Cooperación provincial y de las Comisiones provinciales de Servicios técnicos, con lo que progresivamente se va incrementando el área emancipada de tanta incuria en estos medios rurales, aunque la discordancia de ambos planes y la parquedad de medios malogran en cuantía considerable nuestras ilusiones. 